\title{
NASA Crew Launch Vehicle Flight Test Options
}

\author{
Charles E. Cockrell, Jr.*, Stephan R. Davis**, Kimberly Robinson*, Margaret L. Tuma** \\ National Aeronautics and Space Administration, U.S.A. \\ Greg Sullivan ${ }^{\star \star \star}$ \\ GPS Solutions, Inc., Reno, Nevada, U.S.A.
}

\begin{abstract}
Options for development flight testing (DFT) of the Ares I Crew Launch Vehicle (CLV) are discussed. The Ares-I Crew Launch Vehicle (CLV) is being developed by the U.S. National Aeronautics and Space Administration (NASA) to launch the Crew Exploration Vehicle (CEV) into low Earth Orbit (LEO). The Ares-I implements one of the components of the Vision for Space Exploration (VSE), providing crew and cargo access to the International Space Station (ISS) after retirement of the Space Shuttle and, eventually, forming part of the launch capability needed for lunar exploration. The role of development flight testing is to demonstrate key sub-systems, address key technical risks, and provide flight data to validate engineering models in representative flight environments. This is distinguished from certification flight testing, which is designed to formally validate system functionality and achieve flight readiness. Lessons learned from Saturn V, Space Shuttle, and other flight programs are examined along with key Ares-I technical risks in order to provide insight into possible development flight test strategies. A strategy for the first test flight of the Ares I, known as Ares I-1, is presented.
\end{abstract}

\section{Nomenclature}

CaLV Cargo Launch Vehicle (Ares V)

CFD Computational Fluid Dynamics

CDR Critical Design Review

CEV Crew Exploration Vehicle

CLV Crew Launch Vehicle (Ares I)

CM Crew Module

DFI Development Flight Instrumentation

DFT Development Flight test

DSS Deceleration Subsystem

EDL Entry, Descent, and Landing

EDS Earth Departure Stage

ESAS Exploration Systems Architecture Study

ETM Engineering Test Motor

FSB Five-Segment Booster

FTA Flight Test Article

HXLV Hyper-X Launch Vehicle

IOP Ignition Over-Pressure

ISS International Space Station

KSC Kennedy Space Center

LAS Launch Abort System

LES Launch Escape System

LEO Low Earth Orbit

LH2 Liquid Hydrogen

* Manager, Ares Project Implementation Office, NASA Langley Research Center, Mail Stop 176, Hampton, VA, 23681-2199. Charles.E.Cockrell@nasa.gov

** Flight and Integrated Test Office, NASA Marshall Space Flight Center, JP10, Huntsville, AL.

***President, GPS Solutions, Inc., Reno, NV. gpa@aol.com.
LO2 Liquid Oxygen (LOx)

LSAM Lunar Surface Access Module

MGVT Mated Ground Vibration Test

MLP Mobile Launch Platform

NASA National Aeronautics and Space Admin.

OML Outer Mold Line

PDR Preliminary Design Review

RCS Reaction Control System

RRF Risk Reduction Flight

RSRM Reusable Solid Rocket Motor

PBAN Polybutadiene Acrylonitride

SM Service Module

SRB Solid Rocket Booster

SSME Space Shuttle Main Engine

STS Space Transportation System

TLI Trans-Lunar Injection

TPS Thermal Protection System

TVC Thrust Vector Control

VSE Vision for Space Exploration

WSMR White Sands Missile Range

\section{$\underline{\text { Introduction }}$}

The United States of America President, George W. Bush, announced the Vision for Space Exploration (VSE) in January 2004. The vision outlines a bold program for space exploration with the following components. ${ }^{1}$ 
- Return the Space Shuttle safely to flight. (This objective was accomplished with the STS-114 and STS-121 return-to-flight missions of the Space Shuttle Discovery.)

- Complete the International Space Station (ISS) and retire the Space Shuttle by the year 2010.

- Develop the Crew Exploration Vehicle (CEV) no later than 2014 (with a goal of 2012) and return to the Moon no later than 2020.

- Implement a sustained and affordable robotic and human exploration program and extend human presence across the solar system.

The Exploration Systems Architecture Study (ESAS) was conducted in the summer of 2005 in order to define the design reference missions and vehicle concepts for the CEV, launch vehicles, and other architectures necessary to accomplish the VSE. The results of the ESAS study served as the point-of-departure (POD) vehicle architecture and the basis of the current NASA exploration program. The ESAS architecture sought to maximize commonality between missions to the ISS, the Moon, and Mars. The architecture definition also sought to separate crew and cargo payloads to the maximum extent possible. are:

The major ESAS architecture components

- A Crew Exploration Vehicle (CEV) will be designed to support a crew of four for lunar missions. The CEV will also support missions to the ISS from its initial operational capability through 2016.

- A Crew Launch Vehicle (CLV) designed to launch the CEV into low Earth orbit (LEO). The CLV is now known as the Ares I launch vehicle. The major CEV subsystems are the crew module (CM), service module (SM), and the launch abort system (LAS).

- A heavy-lift Cargo Launch Vehicle (CaLV), now known as the Ares $\mathrm{V}$, designed to launch the additional components needed for lunar missions into LEO. These include an Earth departure stage (EDS) and Lunar surface access module (LSAM). The CEV is designed to dock with the EDS and LSAM in LEO prior to trans-Lunar injection (TLI).

Initial development is focused on the Ares I CLV and the CEV to accomplish the mission for crew and cargo delivery to and from the ISS. A design reference mission for CEV transport to the ISS is shown in Figure 1.

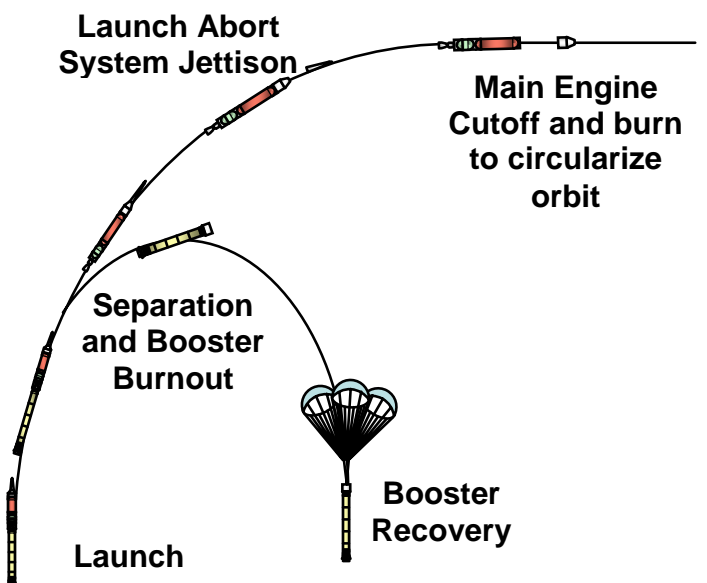

Figure 1. Design reference mission for CEV access to the ISS.

The ESAS final report further outlined a recommended development approach for the components of the CLV, which includes the following: ${ }^{2}$

- A first stage solid rocket booster (SRB), derived from a 4-segment Space Shuttle Reusable Solid Rocket Motor (RSRM). (In trade studies conducted following release of the ESAS final report, the design was modified to a Five-Segment Booster (FSB).) The first stage will also include separation and recover systems, reaction control systems (RCS) for roll control, and SRB nozzle gimbal capability for thrust vector control (TVC).

- A new upper stage, powered by a derivative of the Space Shuttle Main Engine (SSME). (Subsequent trade studies modified the design to a $\mathrm{J}-2 \mathrm{X}$ engine, a derivative of the Saturn $V$ upper stage engine.) The upper stage will also contain LH2 and LO2 fuel tanks, avionics, RCS, and other sub-systems.

The integrated Ares I stack also includes the CEV components. A schematic of the major Ares I hardware elements is shown in figure 2. 


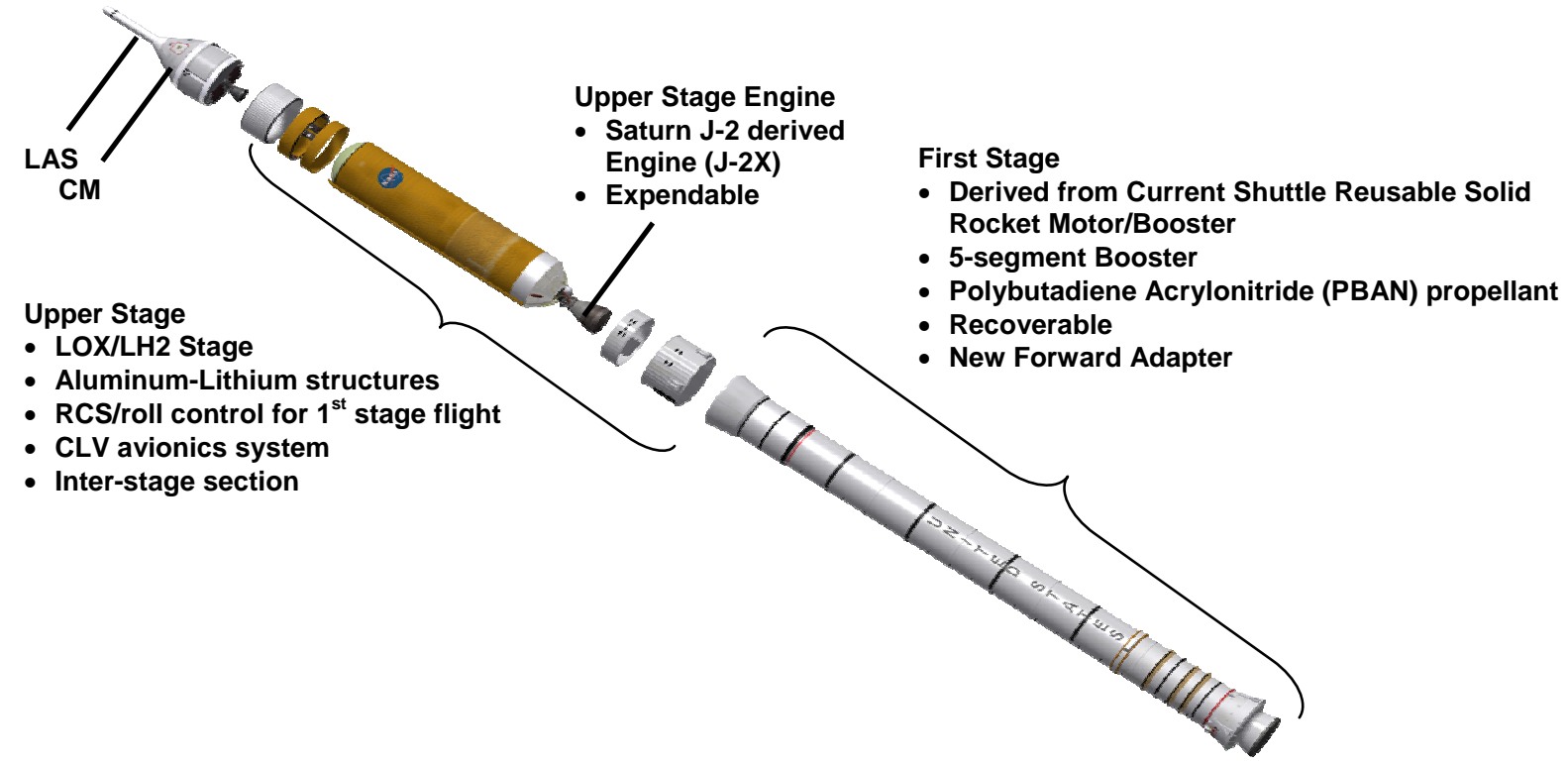

Figure 2. Schematic of the Ares I Launch Vehicle.

\section{$\underline{\text { Role of Flight Testing }}$}

Figure 3 shows a conceptual illustration of the use of test and analysis as part of the overall engineering model verification during the "concept to flight" process. The typical vehicle development process starts with a conceptual design, which includes configuration trades and assessments of uncertainties and key technical risks. Engineering disciplines accomplish their tasks during the design process through analysis, test, and simulation. ${ }^{3}$ Engineering models are matured throughout the development life cycle along with risk and reliability assessments. As the design matures, uncertainty is systematically quantified and decreased to acceptable levels within design margins. Certification of flight readiness is predicated on the ability to validate that system requirements have been met, uncertainties have been quantified, and remaining risks are well understood and accepted.

The NASA systems engineering process defines test and verification methodologies as part of a typical project life cycle. ${ }^{4}$ Verification of system and sub-system requirements is accomplished in stages: development, qualification, acceptance, and preparation for deployment.
The development stage is the period in which a new system is formulated up to the qualification of flight hardware and manufacturing stage. Verification activities during the development stage provide confidence that the system can accomplish mission goals and objectives. Testing provides data which is needed to reduce risk, to define or mature requirements, to design hardware or software, to define manufacturing processes, to define qualification or acceptance test procedures, or to investigate anomalies

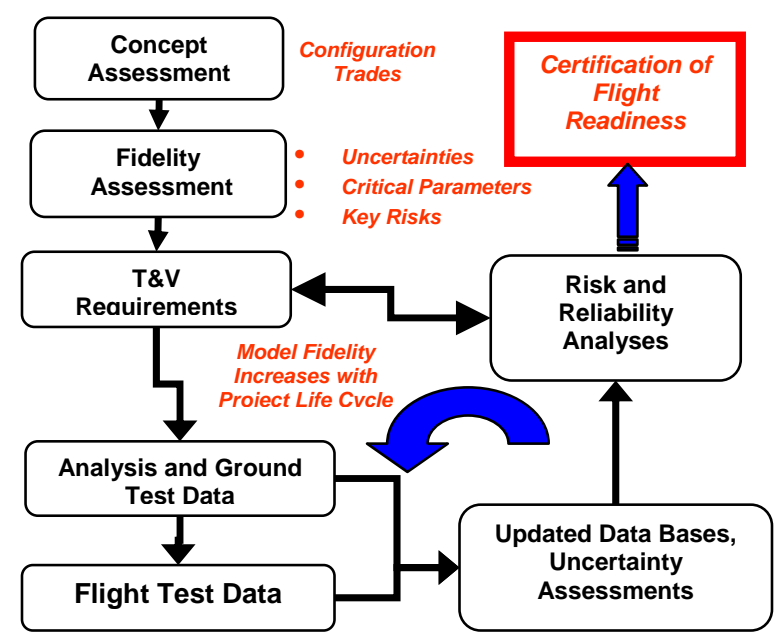

Figure 3. Notional "Concept-to-Flight" Process. 
discovered during prior testing. Verification testing during this stage typically supports the critical design review (CDR).

Flight testing may be performed during the development stage if system requirements cannot be validated, or risks and uncertainties fully quantified, through analysis and ground testing. The benefits of flight testing may be driven by the limitations of test facilities to simulate flight environments, limitations of scale models to adequately simulate flight-like responses, limitations in engineering models to approximate flight conditions, and/or inability of engineering models to simulate complex physical interactions necessary to fully evaluate key aspects of the system design.

A recent example of the use of analysis, ground test, and flight test to mature engineering models and predictive tools is the NASA X-43 Hypersonic Flight Demonstration Program (Hyper-X). The X-43 program demonstrated airframe-integrated supersonic combustion ramjet (SCRAMJET) propulsion in flight at Mach 7 and Mach 10 test conditions. The rationale for a hypersonic airbreathing flight demonstration was that the correct aerothermodynamic and supersonic combustion environments could not be adequately simulated in ground test facilities. Flight data were required to fully validate engineering models used to predict scramjet performance. The X-43 flight program included significant ground testing and analyses to build aero-propulsive performance databases to cover the boost, stage separation, and powered test phases of the flight, as depicted in figure 4. Ground tests included un-powered scaled aerodynamic models, sub-scale and full-scale tip-to-tail propulsion flowpath tests, and static proximity aerodynamic testing to approximate stage separation conditions. Test data were supplemented with computational fluid dynamics (CFD) and engineering code predictions. The final aerodynamic and propulsion data bases were validated through comparisons with flight data. $^{5}$

The development stage is followed by the manufacturing and qualification of flight hardware. During this stage, flight or flight-type hardware is verified to meet functional, performance, and design requirements. Flight verification tests are formal tests with a defined qualification margin as part of the certification program.

\section{ESAS Recommended Flight Test Program}

The ESAS final report made recommendations for a flight test program that included development and qualification testing of the Ares I CLV, the LAS, and the CEV crew module. The ESAS-recommended test program serves a baseline to mature possible flight test strategies for Ares I.

The ESAS report recommended a single development flight test, known as risk reduction flight 1 (RRF-1). ${ }^{6}$ The RRF-1 flight was recommended as a first stage ascent performance test with a mass simulator upper stage, representative CEV test article, and booster recovery systems. The objectives of the RRF-1 were to demonstrate first stage performance, stage separation, and SRB reentry and recovery; and to obtain data to validate engineering models for structural loads, acoustics, and aerodynamics. RRF-1 test objectives also included demonstration of launch
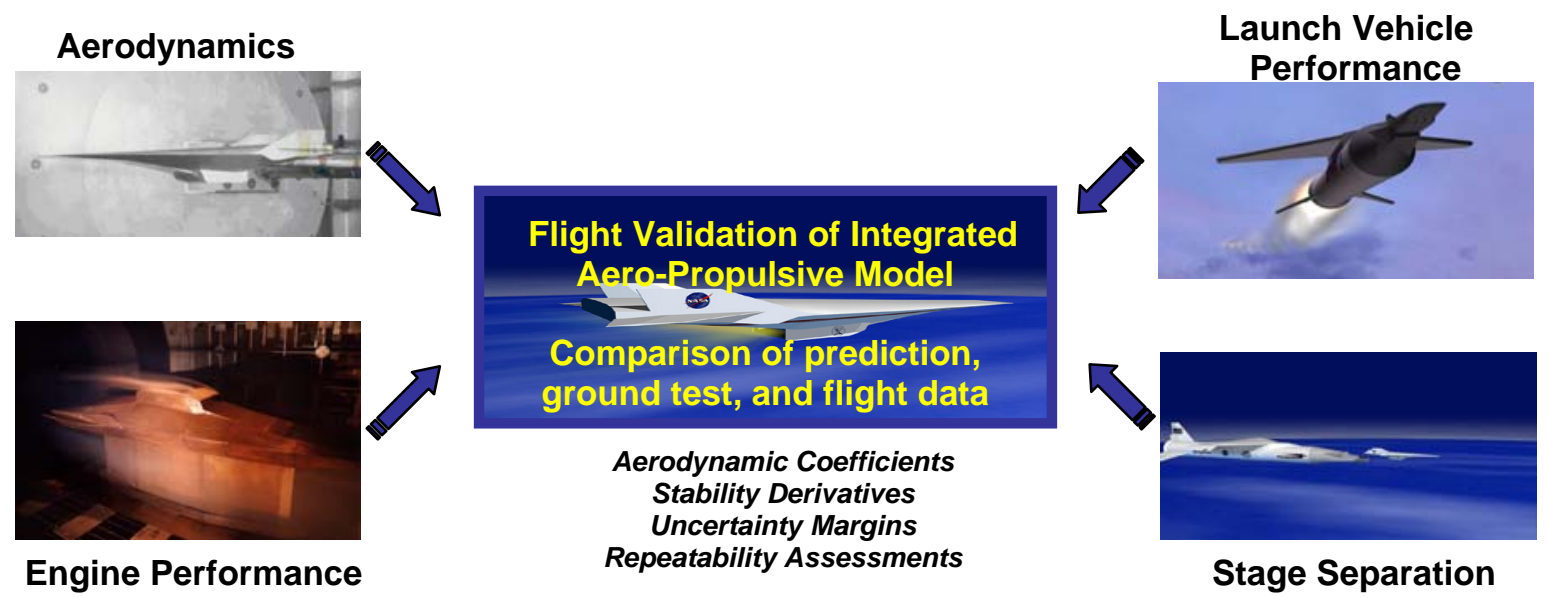

Figure 4. Flight validation of hypersonic airbreathing aero-propulsive models through the $X-43$ Hyper-X Flight Demonstration program. 
vehicle sub-systems, such as avionics, thrustvector control (TVC), and reaction-control systems (RCS). The recommended schedule however, was to conduct the RRF-1 flight after the Ares I system CDR. Significant risk would be incurred if the results of flight testing showed that design changes were needed since the program would be well into the manufacturing phase by that time. Thus, the Ares I program examined strategies for earlier flight testing.

The ESAS recommended flight test program also included two certification flights prior to the first crewed mission to the ISS. The successive RRF-2 and RRF-3 flights were recommended with increasing configuration fidelity and test objectives. A production launch abort system, final flight control system, crew module and service module systems, crew module re-entry and recovery systems, and upper stage engines would eventually be included in order to certify the design for human flight.

\section{Alternative strategies for Ares I flight testing were formulated by examining the following:}

- History of other launch vehicle development programs, such as the Saturn $\mathrm{V}$ and the Space Shuttle.

- Ares I technical risks that may not be adequately mitigated through ground testing and analyses during the development phase.

- Timetable for acquisition of flight test assets, including boosters, upper stages, subsystems, and launch site infrastructure needs.

- Appropriate phasing of launch vehicle, CEV, and LAS flight test objectives.

\section{Lessons Learned}

Previous launch vehicle development programs for human space flight may be examined in order to assess potential strategies for Ares I development flight testing.

\section{Apollo/Saturn V Development}

The Saturn V launch vehicle was developed by the United States in the 1960's to support the Apollo lunar exploration missions. Development of the Saturn V utilized a "building block" approach with many development flight vehicles prior to certification testing and human flight. ${ }^{7}$ A summary of early Saturn flights with a comparison to the ESAS baseline test strategy and schedule if illustrated in figure 5 .

The original Saturn I flew 4 sub-orbital test series flights, also known as "block 1" flights. The block-1 flights, identified in the figure as SA-1 through SA-4, included an inert upper stage, known as the S-IV. Each of these tests were conducted as first-stage ascent tests up to the booster burnout point, but did not test stage separation of the S-IV. The block-1 tests validated ascent performance of the first stage, structural loads, and functionality of gimbaled nozzles on the outboard engines for vehicle stability and control. The SA-4 flight included an intentional check-out of engine-out capability, with 7 out of 8 engines operating.

The Block II flights, identified in the figure as SA-5 through SA-10, included a functional S-IV upper stage. The SA-5 flight was the first orbital vehicle, delivering a prototype crew module to orbit. Each of the SA-6 through SA-10 flights carried prototype crew modules and the SA- 6 carried the first crew module into orbit. The SA-6 and SA-7 tests also jettisoned the launch escape system (LES) after crew module separation from the upper stage. Among other objectives, the block II Saturn I tests also confirmed flight control, propulsion performance, and structural loads.

The next phase of Saturn development included four un-crewed SI-B flight tests. These were prototypes of the Saturn $V$ launch vehicle and included a functional S-IV-B upper stage, powered by a J-2 engine. Test objectives included qualification of prototype crew module (CM) and lunar module hardware. The CM separated and returned to Earth, thus also testing the thermal protection system (TPS). The second SI-B flight included a re-ignition of the SIV-B upper stage engine in orbit. 


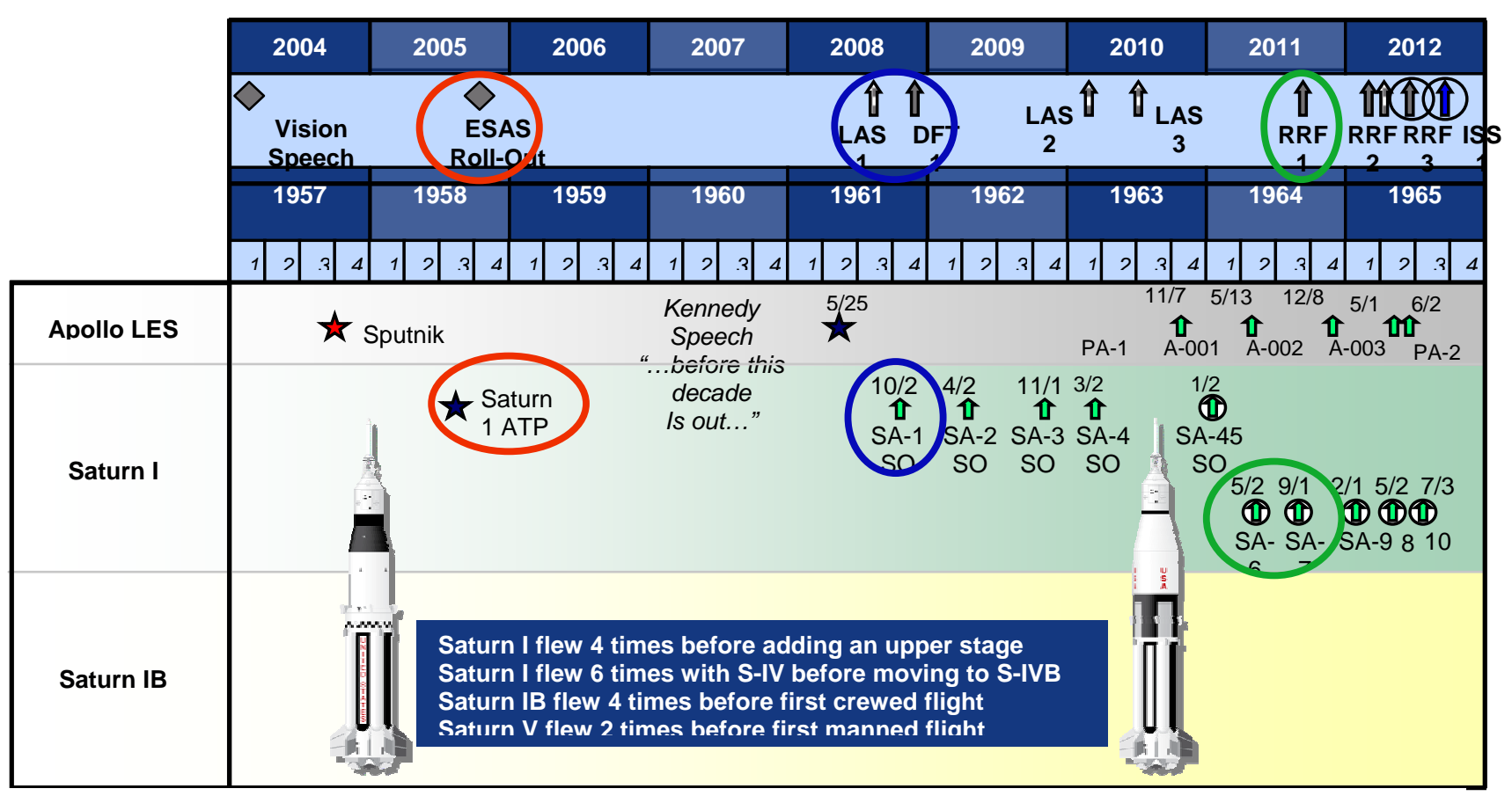

Figure 5. Comparison of ESAS-recommended Ares I development program with Saturn launch vehicle development.

An extensive series of tests was also conducted for the Apollo LES, also shown in figure $5{ }^{8}$ This test series included two pad abort tests at the White Sands Missile Range (WSMR) in 1963 and 1965. As mentioned previously, the Saturn I SA-6 and SA-7 tested a nominal LES jettison mode after CM separation and orbital insertion. There were no additional tests of LES functionality for post upper stage separation abort modes (following first stage burnout). The "Little Joe" test program utilized a booster to test the LES at transonic, maximum dynamic pressure, low altitude, and power-on tumbling boundary abort conditions. The latter condition was designed to demonstrate the ability of the LES canard system to re-orient and stabilize the heat shield after a power-on tumbling abort. Figure 6 shows a photograph of the abort test booster.

A key point in the Saturn flight series is the premise of keeping flight test objectives to a minimum in early tests and building test objectives with successive flights. Additional flight test objectives were added during the program once the key building blocks were well understood. The program utilized sub-orbital tests firsts before adding stage separation, upper stage propulsion, crew module, and launch escape test objectives.

\section{Space Shuttle Development}

The Space Transportation System (STS), also known as the Space Shuttle, conducted four ascent test flights of the Shuttle system, designated STS-1 through STS-4. The key subsystem elements of the Space Shuttle are shown in figure 7 . The main payload on the STS-1 flight, conducted in 1981, was a development flight instrumentation (DFI)

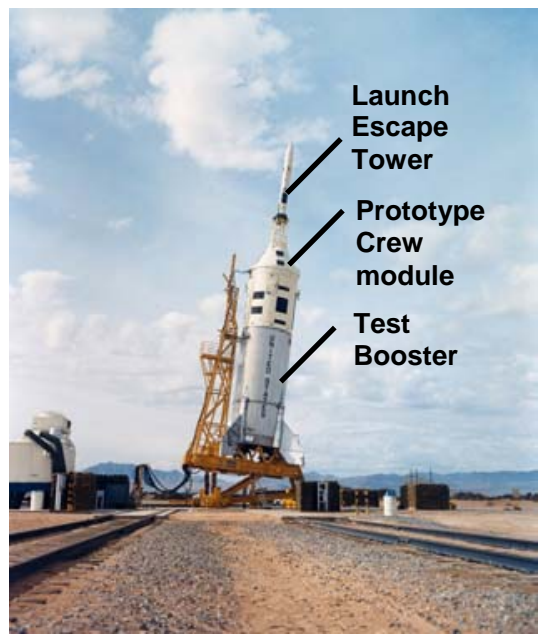

Figure 6. Apollo Launch Escape System (LES) testing. 
package to measure temperatures, pressures, and accelerometer levels on the vehicle. Correlation of engineering models, developed through ground testing, analyses, and component flight tests, with the DFI data was key in declaring the Shuttle "operational" after the STS-4 flight. The Shuttle test flight series was unique in that these flights were crewed.

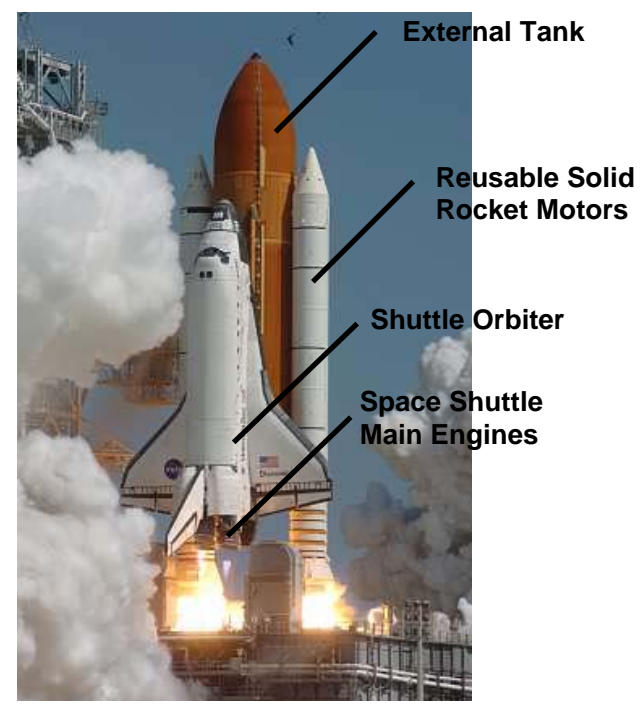

Figure 7. Components of the Space Shuttle System.

Prior to STS-1, the Shuttle conducted extensive test programs on the re-useable solid rocket motors (RSRM), the external tank, and the space shuttle main engines. ${ }^{9}$ Structural dynamics verification was accomplished through scaled testing, analysis, and a full-scale mated ground vibration test (MGVT). ${ }^{10}$ Six drop tests were also conducted for the RSRMs to qualify the deceleration subsystem (DSS). The Shuttle orbiter was also subjected to an extensive entry, descent, and landing (EDL) program. ${ }^{11}$

Lessons learned from the early shuttle flights demonstrate the significance of engineering model validation and impacts to the flight vehicle design. ${ }^{12,13}$ Examples and findings and subsequent design changes to the Space Shuttle based on early flight history, include the following:

- Accelerations measured on the Shuttle orbiter during STS-1 showed that ignition over-pressure (IOP) exceeded the 3-sigma liftoff design environments. Tile damage was also observed on the Orbiter during postflight inspections as a result of over- pressurization. A re-designed water-spray system achieved significant reductions in IOP for STS-2.

- Inadequate modeling of plume interactions between the SSMEs and SRBs led to significant differences in longitudinal forces and moments on STS-1 compared to preflight predictions. As a result, the Shuttle was approximately 10,000 feet higher at SRB separation than the nominal flight profile. The ascent trajectory was altered with a greater negative angle of attack through the maximum dynamic pressure in order to correct this anomaly, but the change in flight trajectory resulted in a $5,000-$ lbm reduction in payload capability.

- $\quad$ STS early flight data indicated significantly higher buffet response on the vertical tail and body flap during transonic speeds. Fortunately, both components had sufficient design margin to accommodate increased buffet loads, but ascent environments were updated based on flight measurements.

- $\quad$ Coupling with the liquid oxygen (LOx) tank slosh modes led to differences in 1st-mode bending frequencies compared to pre-flight predictions.

- There was an ascent performance shortfall of approximately $10,000-\mathrm{lbm}$ as a result of loads increases, inaccurate aerodynamic predictions, and other flight environment measurements compared to design predictions. A Shuttle enhancement program subsequently realized back some payload capability gains with changes to the space shuttle main engines, external tank, and RSRMs; as well as Orbiter weight reductions.

\section{Other Flight Programs}

The first flight of the $X-43$ ended with a failure of the booster to deliver the $X-43$ vehicle to the Mach 7 test condition. The Hyper-X Launch Vehicle (HXLV) failure occurred due to a control anomaly, characterized by diverging roll oscillation, during the transonic pull-up maneuver. ${ }^{14}$ The major contributors were found to be modeling inaccuracies in the fin actuation system and aerodynamics, and insufficient variations of modeling parameters via parametric uncertainty analyses. The 
aerodynamic modeling uncertainties resulted from misinterpretation of ground test data due to insufficient data, especially in regions where non-linear effects may dominate, and unmodeled outer mold line changes associated with the thermal protection system (TPS). The flight mishap could only be re-produced when all of the modeling inaccuracies with uncertainty variations were incorporated in the simulation models conducted during the mishap investigation. After performing additional ground testing and making changes to the booster, fin actuation system, flight control system, and flight profile, the X-43 was able to successfully return to flight.

\section{Ares I Risk Reduction Objectives}

Key factors in determining development flight test strategies are the technical risks that may be candidates for risk mitigation through flight testing.

The five-segment solid rocket booster (FSB), which forms the first stage of the Ares I, will be a new flight system derived from heritage Space Shuttle hardware. Significant hardware developments are required to upgrade the existing four-segment SRB. These include the addition of a fifth propellant segment, new propellant grain structure, new structural subsystems, new electrical and instrumentation systems, and new separation and deceleration subsystems. The FSB integration with the Ares I launch vehicle system is significantly different than the STS. The Ares I "in-line" concept will lead to low bending mode frequencies, which in turn will present significant challenges for the flight control system design and validation. Additionally, the SRB nozzles are used to provide thrust-vector control (TVC) for pitch stability and reaction control systems (RCS) are used for roll stability on ascent. Validation of roll torque to size and qualify RCS systems is a key technical risk which could be mitigated with flight measurements.

Stage separation of the Upper Stage occurs after first stage burnout. The Ares I flight profile has a stage separation point at a higher Mach number and altitude, and a lower dynamic pressure, than the current Shuttle system. Therefore, re-design of deceleration and recovery systems will be required. Flight testing provides an opportunity to demonstrate new deceleration and recovery systems at appropriate scale and to obtain flight measurements for descent aerodynamics, flight dynamics, thermal, and structural models through parachute deployment and recovery. Inclusion of stage separation test objectives will also provide flight measurements for proximity aerodynamics and environments in the vicinity of the $\mathrm{J}-2 \mathrm{X}$ engine following separation (to validate altitude starting conditions). Upper stage flight dynamics and structural stability after separation can also be measured.

Since the integrated Ares I launch vehicle stack includes the CEV crew module, service module, and LAS, test objectives for these systems may also be considered in Ares I Development Flight Test (DFT) planning. The LAS must function successfully from pre-launch conditions through orbital insertion. During ascent, key points which may require validation of LAS functionality include maximum dynamic pressure condition, transonic conditions, and high-altitude (post stage separation) abort. Demonstration of the high-altitude abort scenario from the upper stage could be included as a flight test objective along with Ares I test objectives. CEV test objectives may also include aerodynamic performance, stability and control; TPS survivability; and functionality of landing and recovery systems following abort scenario demonstration.

Successfully establishing operational capability of the Ares I necessitates the need for new ground processing, launch operations, infrastructure, and processes. Ares I ground processing and launch operations will be conducted from NASA Kennedy Space Center (KSC) in Cape Canaveral, Florida. Development flight testing provides an opportunity to become familiar with ground operations for a new vehicle and make improvements before certification and operational status.

One of the key benefits of flight testing is that it provides simultaneous testing in a real environment of multiple subsystems and complex interactions which cannot be adequately modeled in engineering analyses or ground test facilities. Figure 8 shows a notional illustration of how integrated engineering models for aerodynamic, thermal, structural, and control system performance through first stage ascent, stage separation, and booster descent and recovery may be developed through ground 
- Vehicle Environments

- Wind Tunnel Test Data

- Loads, Thermal Environment Predictions

- Pre-Flight Databases

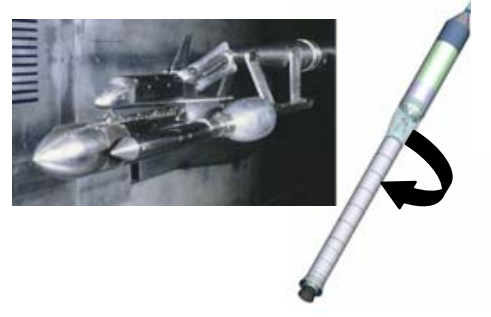

- First Stage Performance

- Propulsion performance.

- Flight control laws.

- TVC Models.

- Roll Torque Predictions and RCS Models.

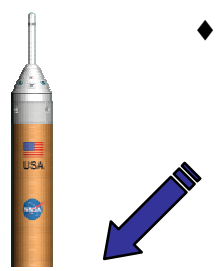

- Structural Integration

- Analysis of load paths, dynamics.

- Component-level modal testing.

- Aeroelasticity Wind Tunnel Test and Analysis.

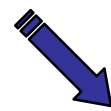

Flight Validation of Integrated Aero, Structures, and Performance Models Comparison of prediction, ground test,

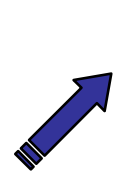
and flight data

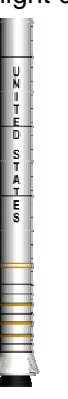

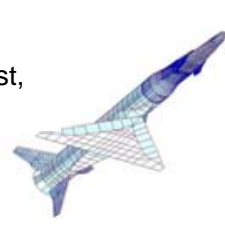

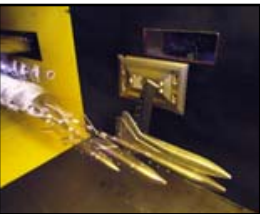

- Stage Separation

- Static and Time-Dependent CFD.

- Quasi-static Wind-Tunnel testing for interference aero.

- Descent Aerodynamic and Thermal Loads.

- Parachute Deployment Models and Testing

Figure 8. Integration of vehicle engineering models through ground testing and analysis with flight test validation through first stage ascent, stage separation, and booster descent and recovery.

testing and analysis, and validated through flight measurements.

\section{Options for Ares I CLV Flight Testing}

The VSE established an objective of conducting the first crewed mission of the CEV to the ISS no later than 2014, but with a goal of 2012. Developmental flight testing with the goal of informing the Ares I design process is of optimal value if conducted prior to the critical design review CDR. Therefore, strategies for early flight testing focus on windows of opportunity in late 2008 or early 2009. Assessments of flight test options must weigh the technical value of performing a flight test with the associated schedule, budget, and technical risks.

Phasing of Ares I, LAS, and CEV flight test objectives may be considered in order to provide the best approach for development of each system. Based on assessments of Ares I technical risks, the following possible test objectives may be formulated.
- First stage ascent performance, including measurement of roll torque, validation of the basic flight control system methodology, and measurement of flight data to validate aerodynamic, thermal, structural, and other engineering models.

- Stage separation, including proximity aerodynamics, and measurement of environments for the upper stage engine through separation.

- Demonstration of FSB descent, deceleration systems, and recovery operations.

- Demonstration of upper stage un-powered and powered performance after separation.

- Demonstration of LAS functionality after stage separation.

- Demonstration of CEV re-entry, descent, and landing following crew module separation.

There are multiple options for a first stage flight test booster to achieve development test objectives. These include an existing 4- 
segment RSRM, obtained from the Shuttle program, a prototype FSB, or various hybrid options. The advantage of a flight test configuration with the four-segment booster is that an initial DFT could be done prior to 2009 without significant risk. However, there would significant differences in first stage performance compared to the Ares I operational vehicle with an FSB. Development of a prototype FSB for flight testing prior to CDR would be challenging from both a schedule and budget perspective. A 5-segment engineering test motor (ETM) is available from ground test programs. ${ }^{15}$ The ETM may provide more representative boost performance than a 4-segment RSRM, but would require a substantial effort to re-configure the test article as a flight system. A hybrid option is to utilize an existing 4-segment RSRM with an added inert segment. This option is referred to as the 4-segment $\mathrm{XL}$ booster. Preliminary analysis shows that this configuration would provide a representative dynamic response, which would provide a meaningful test of a prototype Ares I control system. The 4-segment $\mathrm{XL}$ option does not match the aerodynamics, trajectory, and ascent performance of the FSB, but does provide the capability to match a limited number of specific trajectory points.

Several options also exist for upper stage DFT flight test articles (FTA). Any FTA design should replicate the outer mold line (OML) and mass properties of the Ares I flight vehicle configuration in order to provide meaningful flight data to validate aerodynamic and structural models. However, the upper stage FTA need not include all flight-like sub-systems in order to achieve the basic test objectives of demonstrating first stage performance and control system functionality. Options for upper stage FTA design and development are based primarily on the inclusion of post-separation test objectives. The options include the following.

- Inert simulators for the upper stage, CEV, and LAS. This design concept assumes no post-separation test objectives.

- Inert simulators for the upper stage and CEV, and a functional LAS that would demonstrate the high-altitude abort scenario by separating the crew module from the upper stage after first stage burnout and stage separation.
- An Inert upper stage, with both a functional LAS and a prototype crew module, which would demonstrate functionality of the CEV TPS, RCS, deceleration, and landing systems for the CEV after a high-altitude abort and subsequent re-entry and landing.

- A prototype upper stage that would validate structural integration with flight-like structural sub-systems, fuel tanks, and load paths.

- A prototype upper stage engine which would enable demonstration of second-stage performance up to orbital insertion.

Implementing each of these options, with the exception of the fully inert mass simulator option, would likely require designs and subsystems that would not be mature enough by the Ares I CDR to conduct a meaningful test. The mass simulator option represents a reasonable level of technical, budget, and schedule risk for an initial DFT. Higher-fidelity booster and upper stage designs could be utilized in subsequent flight tests as sub-systems are matured and additional test objectives are added.

Therefore, the optimal strategy is to conduct an initial Ares I DFT before mid-2009 to provide a representative test of the first stage booster performance, separation, and recovery, as illustrated in figure 9. Such a development test would also obtain data to validate the Ares I flight control system design as well as aerodynamic, structural, and thermal models. Additional test objectives will be added in subsequent flights.

\section{Ares I-1 Flight Test Strategy}

The first Ares I DFT, now known as Ares I-1, will utilize the 4-segment XL booster option

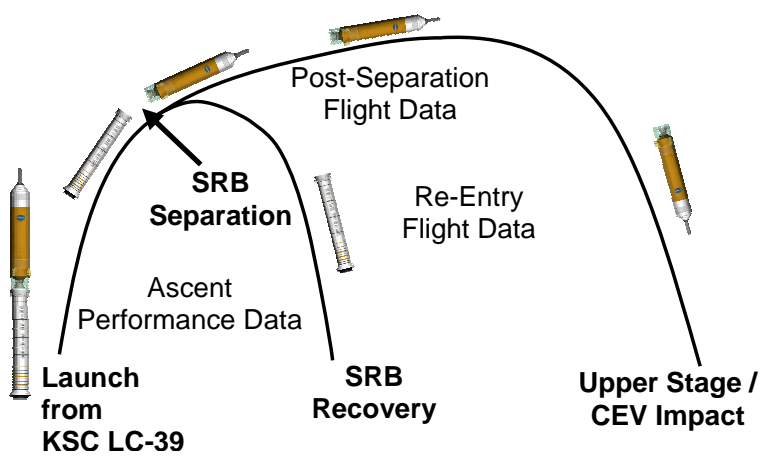

Figure 9. Reference mission concept for initial Ares I development flight test. 
for the first stage. The $\mathrm{XL}$ booster will approximate the full length, structural dynamics, and flight dynamics of the Ares I operational vehicle and will test the Ares I flight control system through the first stage burn and separation. The boost trajectory will be tailored to match specific points. The booster will be recovered and provide measurements of descent performance and a demonstration of prototype deceleration systems. The upper stage, CEV, and LAS will be inert simulators, approximating the outer mold line (OML), mass properties, and moments of inertia. Figure 10 illustrates the key components of the Ares I-1 flight test vehicle.

The Ares I-1 will be conducted at NASA Kennedy Space Center (KSC) at the existing Launch Complex 39 with minimal modifications. This allows the Ares I-1 to take place while Space Shuttle operations are still proceeding. Substantial modifications to the launch vehicle infrastructure at KSC will take place prior to the first Ares I human flight. Figure 11 illustrates vehicle stacking concepts on the existing mobile launch platform (MLP) and available access points with the existing launch pad infrastructure.

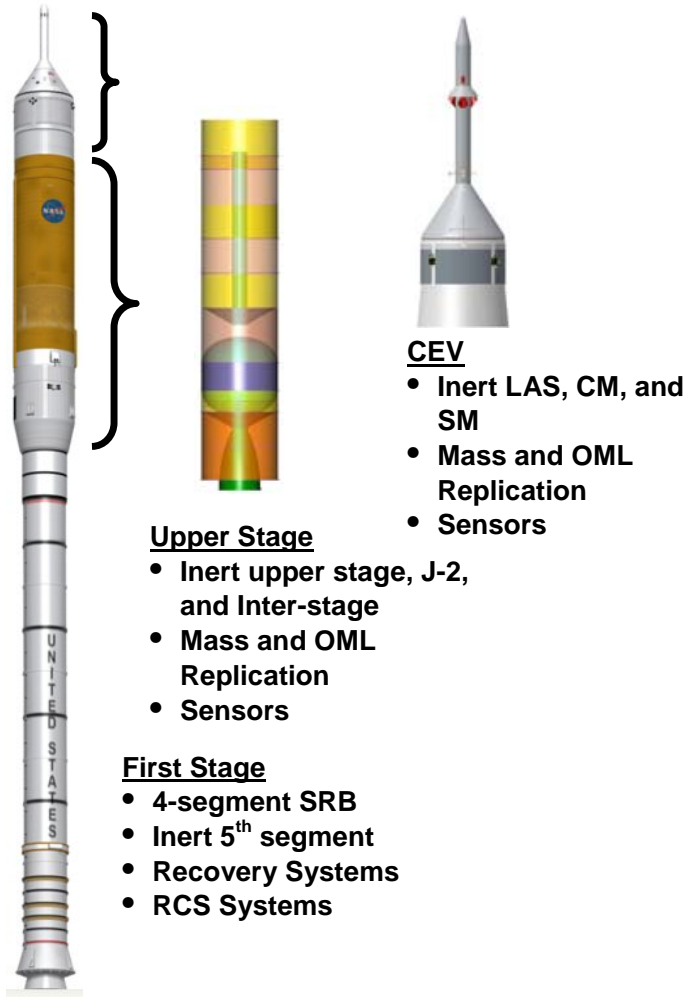

Figure 10. Components of the Ares I-1 development flight test vehicle.
The Ares I-1 flight test strategy addresses the following key technical risks:

o Demonstration of ascent flight control system performance with a dynamically similar first-stage vehicle (and second stage components).

o Demonstration of nominal stage separation, clearances, and environments.

o Demonstration of launch processing time and required resources, as well as built-in test avionics.

In addition, the first Ares I development flight test will obtain flight data to provide risk reduction in the following areas:

o Demonstration of first-stage ascent performance, parachute deployment, separation, and entry dynamics.

o Measurement of integrated vehicle roll torque due to 1st stage motor performance.

o Measurements to validate other engineering models where complex physical interactions can be measured in representative flight environments.

Subsequent Ares I flights will add additional objectives, including CEV/LAS performance during a post-staging abort from abort initiation to water landing and recovery; five-segment solid rocket booster performance; and protoflight upper stage performance; and $\mathrm{J} 2-\mathrm{X}$ engine performance to achieve orbital insertion of the CEV.
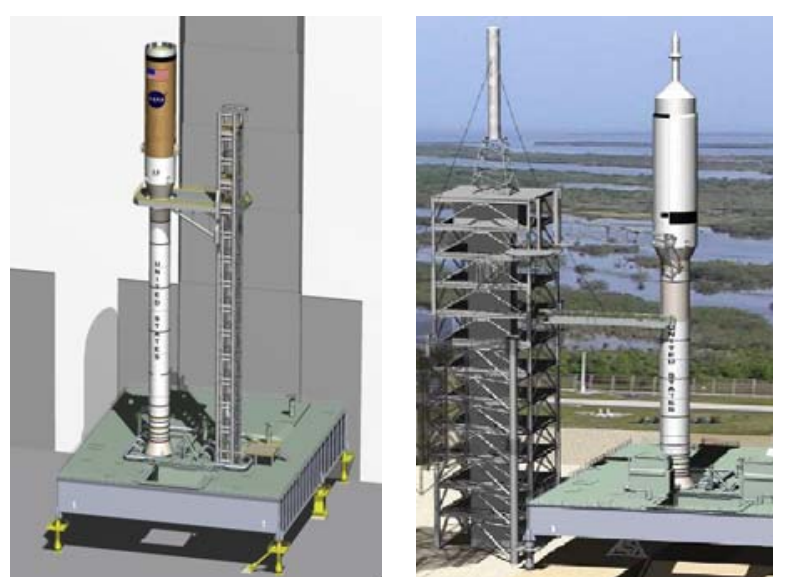

Figure 11. Depiction of vehicle stacking and operations at NASA Kennedy Space Center. 


\section{Concluding Remarks}

The Ares I Crew Launch Vehicle (CLV) is being developed to provide the capability to launch the Crew Exploration Vehicle (CEV) into Earth orbit. This development program is part of the vision for space exploration (VSE) and will achieve the objectives of providing crew and cargo access to the International Space Station (ISS) following retirement of the Space Shuttle, and, together with the Ares $\mathrm{V}$ Cargo Launch Vehicle, will provide the launch capability for future lunar exploration. Flight test strategies were formulated for the Ares I vehicle by examining lessons learned from Saturn $V$ and Space Shuttle development, key technical risks for Ares I development, phasing of test objectives, and available assets. An initial development flight test (DFT), known as Ares I1 , will be conducted in April 2009. Ares I-1 will utilize a four-segment solid rocket booster (SRB) with an added inert segment to approximate the flight dynamic, structural response, and control system response of the Ares I operational vehicle with a five segment booster (FSB). The Ares I-1 upper stage, CEV, and launch abort system (LAS) test articles will be inert mass simulators. Flight test objectives will focus on first stage performance, stage separation, and booster recovery. Additional test objectives will be added in subsequent flights, including FSB performance, prototype upper stage performance, high-altitude LAS demonstration, and upper stage engine demonstration. The Ares I will launch the first human flight of the CEV to the ISS no later than 2014.

\section{References}

1. The Vision for Space Exploration. National Aeronautics and Space Administration, Washington, D.C., February 2004.

2. NASA Exploration System Architecture Study (ESAS) Final Report. NASA Report TM-2005-214062, Chapter 6: Launch Vehicles and Earth departure stages, pp. 361-510, November 2005.

3. Blair, James C.; Ryan, Robert S.; and Schutzenhofer, Luke A. Launch Vehicle Process: Characterization, Technical Integration, and Lessons Learned. NASA TP-2001-210992. National Aeronautics and Space Administration, Washington, D.C., 2001.
4. NASA Systems Engineering Handbook. NASA Report SP-6105. National Aeronautics and Space Administration, Washington, D.C., June 1995.

5. Ferlemann, Shelly M.; McClinton, Charles R.; Rock, Kenneth E.; and Voland, Randall T. Hyper $=X$ Mach 7 Scramjet Design, Ground Test, and Flight Results. AIAA Paper 2005-3322, Presented at the $13^{\text {th }}$ AIAA/CIRA International Space Planes and Hypersonics Technology Conference, Capua, Italy, 2005.

6. NASA Exploration System Architecture Study (ESAS) Final Report. NASA Report TM-2005-214062, Chapter 10: Test and Verification, pp. 645-665, November 2005.

7. Bilstein, Roger E. Stages to Saturn: A Technological History of the Apollo/Saturn Launch Vehicle. NASA SP-4206, Chapter 11, pp. 323-349. National Aeronautics and Space Administration, Washington, D.C., 1980.

8. Townsend, Neil A. Apollo Experience Report: Launch Escape Propulsion Subsystem, NASA Report TN D-7083, March 1973.

9. McIntosh, Gregory P. and Larkin, Thomas P. Space Shuttle's Testing Gauntlet. Aeronautics and Astronautics, vol. 14, pp. 44-56, January 1976.

10. Modlin, C. Thomas Jr. and Zupp, George A. Jr. Space Shuttle Dynamics Characteristics: The Analysis and Verification, Proceedings of the Space Shuttle Technical Conference, Part 1, pp. 325-324, January 1985.

11. Baker, David. Evolution of the Space Shuttle: 5. Approach and Landing Test Program. Spaceflight, vol. 19, pp. 213-217, June 1977.

12. Bejmuk, Bo. Space Shuttle Integration: Lessons Learned, Presentation to Space Shuttle Personnel, November 2005.

13. Jenkins, David. R. Space Shuttle - The History of Developing the National Space Transportation System. Walsworth Publishing, Marceline, MO, 1997. 
14. Report of Findings: X-43A Mishap Investigation Board, volume I, September 2002.

15. Nielsen, D.; Townsend, J.; Kappus, K.; Driskill, T.; Torres, I.; and Parks, R. A 5Segment Derivative of the Space Shuttle Solid Rocket Booster, Presented at IMAC XXIII, February 2005. 